\title{
Reciprocidad y trabajo en la tecnología social \\ de una economía urbana popular
}

\author{
Nicolás Gómez Núñez \\ Universidad Central de Chile, Santiago, Chile. \\ Email: nicolas.gomez@ucentral.cl
}

\begin{abstract}
Resumen $^{1}$ : Este artículo presenta los resultados de una investigación que buscó responder la siguiente pregunta, ¿Cuáles son las características de las relaciones de reciprocidad y de la división del trabajo que están en las tecnologías sociales de las organizaciones económicas que realizan un emprendimiento asociativo de trabajo autogestionado? La búsqueda de respuestas se hizo mediante un trabajo de campo desde 2013 a 2015, con 56 organizaciones económicas que usan la calle Estados Unidos en la comuna de Huechuraba en la Región Metropolitana de Chile, para crear un mercado.

El estudio mostró que la tecnología social está basada en la convivencia, y en una ética compuesta por los valores de: libertad, transformación de las cosas en dinero en efectivo y en la obligación de brindar asistencia a la persona que vive una necesidad.

Palabras claves: Tecnología social, reciprocidad, división del trabajo, ética social y comunidad efectiva.
\end{abstract}

\section{Reciprocity and work in social technology of a popular urban economy}

\begin{abstract}
This article presents the results of a study that sought to answer the following question: What are the characteristics of the relationships of reciprocity and of the division of labor that are present in the social technologies of economic organizations that carry out self-managed associative venture work? The search for answers wasperformed through fieldwork from the year 2013 to 2015, with 56 economic organizations that use EstadosUnidos Street in the district of Huechuraba in the Metropolitan Region of Chile, to create a market.

The study showed that social technology is based on cohabitation, and on ethics composed by the following values: freedom, transformation of things into cash and the obligation to assist the person who is in need.
\end{abstract}

Keywords: Social technology, reciprocity, division of labor, social ethics and effective community

\section{Reciprocidade e de trabalhoemtecnologia social em uma economia popular urbana}

Resumo: Este artigo apresenta os resultados de umainvestigação que buscou responder à pergunta: Quaissão as características das relações de reciprocidade e 
divisão do trabalhos ão tecnologias sociais de organizaçõ eseconômicas que realizam um trabalho de empresa associativa I auto-gerida? A procura de respostas foifeito através de trabalho de campo 2013-2015, com 56 organizações econômicas utilizando US rua Huechuraba na Região Metropolitana do Chile, para criar um mercado.

O estudomostrou que a tecnologia social é baseada na coexistência e de forma ética composta dos seguintes valores: liberdade, transformação das coisas em dinheiro e a obrigação de ajudar a pessoa que vive uma necessidade.

Palavras-chave: Tecnologia Social, de reciprocidade, divisão do trabalho, ética social e comunitária eficaz

$* * *$

\section{Introducción}

Toda economía ha sido forjada por el obrar colectivo. En dicho transcurso las personas han tenido que aprender a crear organizaciones. Esta cualidad aparece más clara cuando se trata de una comunidad que ha inaugurado un mercado sobre relaciones de reciprocidad y distribución.

Este proceso es el que estudiamos desde 2013 hasta 2015, en 56 organizaciones económicas que han surgido motivadas por el trabajo y que logran administrar un emprendimiento asociativo autogestionado. Para indagar en su vida económica nos hicimos la siguiente pregunta, ¿cuáles son las características de las relaciones de reciprocidad y de su división del trabajo?, e iniciamos la búsqueda de respuestas mirando a través de la noción de tecnología social, la cual nombra las relaciones reglamentadas basadas en la reciprocidad y el trabajo que facilitan usar técnicas de producción, intercambio y distribución (Sen, 1987; Forni, 1992).

Esta forma de abordar un caso de la economía urbana latinoamericana, asume que hay "recursos no convencionales" que son renovables gracias a su uso intensivo (Max-Neef, 1993, p. 109). Entre esos recursos se encuentran los que se reúnen en la noción de Economía Popular, por ejemplo: comensalidad, acumulación de valores (Razeto, 1984), identidad y reconocimiento (Hardy, 1985). Desde este punto de vista, las organizaciones que hemos estudiado nos muestran prácticas que comunitarizan el medio social urbano.

\section{Tecnología social}

La tecnología social fue tratada desde una revisión bibliográfica que ayudó a conocer la trayectoria de la categoría, los usos que se le ha dado en las políticas públicas y los axiomas que ayudan a producir conocimiento sobre la construcción colectiva de respuestas a los problemas individuales (Véase, Gómez, 2014). Desde aquí, contamos con un concepto operativo definido según dos niveles. El primero se refiere a su "comunidad efectiva" 
(Lomnitz, 1976, p.40), la cual permite que sus integrantes se comprometan en "el obrar colectivo que impide el cálculo y fomenta una praxis espontánea, irreflexiva e inintencionada que reproduce el sentido de integración del mundo de vida” (Moreno, 2006, p. 48). En esos términos, esa comunidad es un tipo de "cohesión social efectiva" (Granovetter, 1973, p. 12) y una forma de “integración sociotécnica” (García, 2004, p. 430) que tiene la capacidad de fijar fronteras en sus relacionales y contenidos (Lozares, Verd y Barranco, 2013). En su interior hay posiciones que gozan del reconocimiento, y a todas ellas les es común que sus competencias son aprendidas en la división del trabajo; mientras que otras posiciones se sustentan en la reciprocidad alternante e indirecta, reciprocidad alternante y directa y reciprocidad total (Mauss, 2002; Godelier, 1998; Bourdieu, 2007).

El segundo nivel de la tecnología social es su saber hacer orientado a resolver los problemas intersubjetivamente relevantes (Luckmann, 2008, pp. 203-206), para lo cual se mezclan conocimientos populares y técnicocientíficos (Dagnino, Cruvinel y Tahan, 2004) de acuerdo a un "contexto estructurado de significados” (Schütz, 1993, p.54). Desde ahí emerge su dimensión cognitiva expresada en dos estructuras simbólicas. Una de ellas está dedicada a elaborar conocimientos sociotécnicos a partir de las clasificaciones de las experiencias de los integrantes de las organizaciones económicas. Y otra estructura simbólica que reproduce esos sentidos, a través de mandatos culturales cuya función es mantener la coherencia de su emprendimiento asociativo de trabajo autogestionado.

\section{Metodología del estudio}

El trabajo de campo se hizo en la cola que se realiza, desde hace más de 8 años, en la calle Estado Unidos (EEUU) en la comuna de Huechuraba, Región Metropolitana de Santiago de Chile; sus integrantes no pagan patente y posee dos tipos de organizaciones económicas que la constituyen: unas dedicadas a vender artefactos recolectados en los desechos urbanos, por esta cualidad se les llama cachureros, mientras que las otras organizaciones venden al detalle los productos que compra al mayoreo.

La cola de la calle EEUU sólo se realiza el día domingo, incorpora a 112 personas si estimamos que cada uno de sus 56 puestos posee 2 integrantes. Luego, si consideramos el total de colas de Huechuraba, la estimación llega a 672 personas en 336 puestos. La cola vuelve a repetirse en las 47 comunas de la región, excepto en: Vitacura, Las condes, Lo Barnechea, La Reina y Providencia. Aplicando la misma estimación, llegamos a los siguientes resultados: habrían 235, con 13.160 puestos donde trabajarían 26.320 personas. Este cálculo devela dos sesgos. Primero, la suposición que cada vez que hay feria de abastos habrá una cola con 56 puesto. Sin embargo, nuestro estudio mostró que los coleros participan en otras formas económicas fuera de Huechuraba, como el "persa de Zapadores", que no está asociado a una feria de abastos y se extiende por más de mil metros, o sea, puede tener 500 puestos aproximadamente. 
Segundo sesgo, la reflexión sobre el papel de las colas en las dinámicas económicas locales, se sostiene en hipótesis que no han sido contrastadas y los estudios realizados han tenido que discernir su situación dentro del sector informal. Entonces, ante la ausencia de datos, las colas son subsumidas a las ferias de abastos o libres, las cuales se basan en la economía familiar campesina, en la reventa de productos agrícolas y en el cumplimiento de las ordenanzas municipales. A pesar de este sesgo, hay consenso en que las colas son una expresión del "comercio informal de los pobres" que enfrenta la "crónica crisis del empleo asalariado en Chile” (Salazar, 2003, pp.103-110); y para estimar su envergadura también se ha recurrido a la cantidad de patentes pagadas por las ferias libres (Márquez, 2004).

Para revisar la vida económica de la cola de la calle EEUU, implementamos las técnicas de observación y conversación, y las herramientas de registro de campo, lista de cotejo y pauta de preguntas semiestructurada. La muestra se construyó en un proceso de bola de nieve considerando la reputación de los integrantes, si ayudaban a otros y participaban en la gestión política de la cola. En el análisis de los datos se utilizó la historia de vida, análisis estructural de contenido y análisis estructural de redes sociales, sobre 54 entrevistas.

\section{La elaboración colectiva de la cola}

La cola está conformada por tres sectores, así como se muestra en la Tabla 1. El sector pasillo, es por donde transitan las personas que son los potenciales compradores. El sector 1, es el puesto donde están las cosas que se ofrecen y se disponen en conjuntos según sus usos. El sector 2, se ubica entre el puesto y la muralla de las casas, ahí se realiza: la comensalidad, la espera y es la bodega.

El inicio de la cola es posible cuando pasan las personas que se dirigen a la feria de abastos para comprar las cosas para la semana. Así ocurre un tiempo que se nombra como: viene un "choclón de gente". Aquí abundan las preguntas sobre las cosas, las ventas, el cambio de dinero, el regateo, saludos y las miradas. Luego, al disminuir el flujo de gente, se comienza a evaluar la posibilidad de guardar el puesto, se ponen las cosas dentro de las cajas, se saca el medio de transporte y se las sube,las cajas son amarradas, se retira el plástico, se limpia el lugar, se ordena la basura y los coleros emprenden su marcha hacia sus viviendas. Una vez que se han ido vuelve la calle EEUU. 
Tabla 1

Coleros y sectores de la cola de la calle EEUU

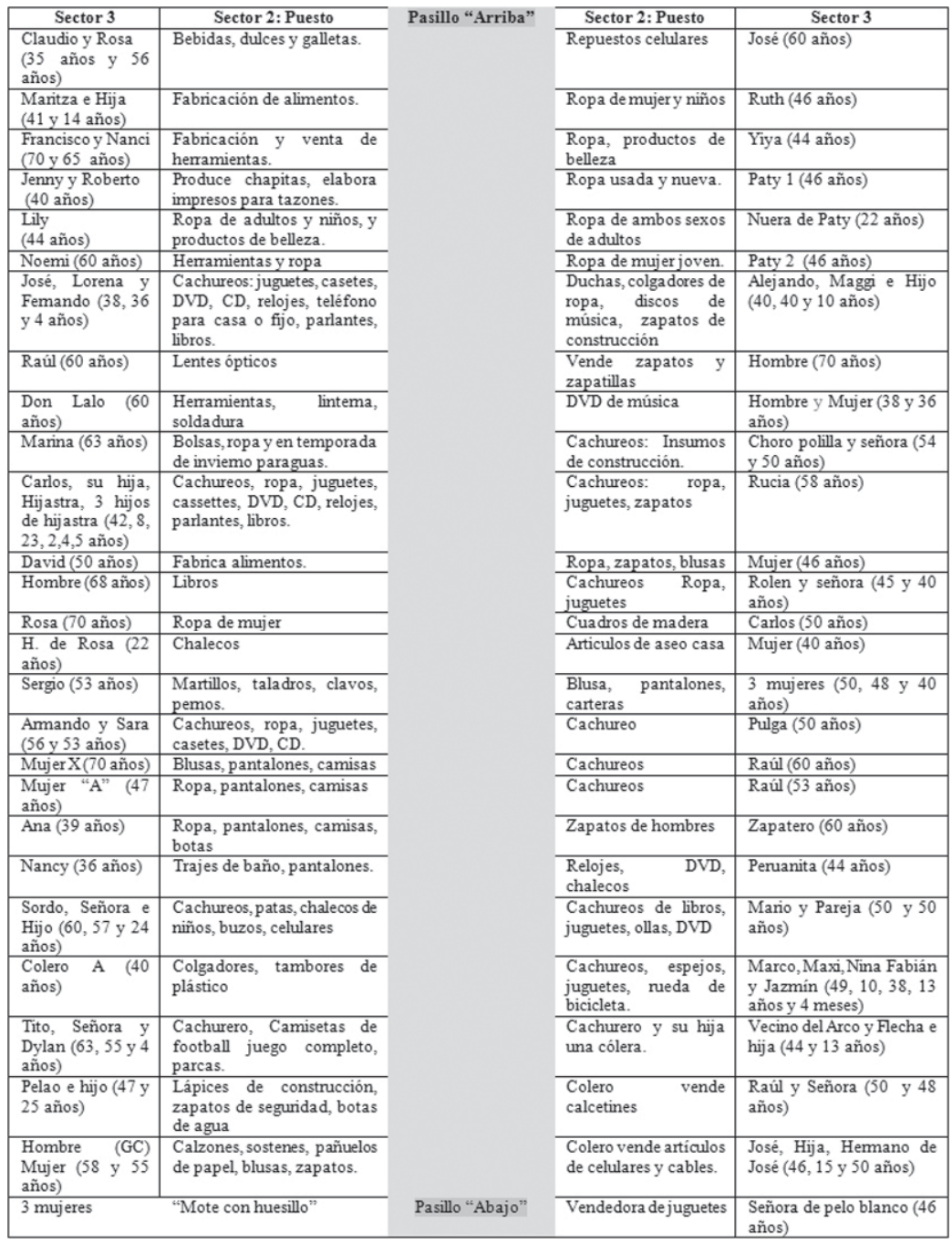

Fuente: Elaboración propia

\section{Trayectorias de vida de los coleros}

Las rememoraciones fijan el nacimiento de la cola hacia fines de la década del setenta del siglo pasado, cuando la gente se estaba ambientando. 
Ahí los desempeños fueron individuales: “cada uno en su ladito” y donde hubo envidia entre los que tenían ladoy los que no tenían. Ese tiempo cambia cuando los primeros integrantes se asumen como compañeros y vecinos, y valoran sus posesiones materiales y simbólicas, lo que se expresa como: "mi vecino me cuida ese lado" y "yo le cuido a mi vecino". Parafraseando a Godelier (1976, p.162), es en este momento donde las actividades individuales empalman con una institución que ayuda a reproducir el regateo y la estimación de precios porque, de lo contrario, la ausencia de esa institución desalentaría las prácticas individuales.

Esta vecindad y compañerismo se despliega en tres generaciones. Para 2015 las mujeres y hombres que inauguraron la actividad tienen entre setenta y ochenta años, y hay dos tipos de trayectorias que los definen. La primera es la de cachurerocachurero con cambio de ocupación, está marcada por una invitación que se hace en su red parental y de amistad para participar en una plaza laboral apatronada en La Vega y en la construcción, contrae matrimonio y tiene más de tres hijos, participa en la toma de terrenos construyendo la población junto a su mujer. Esta etapa finaliza cuando queda cesante. La segunda etapa arranca desde una evaluación que considera que esa cesantía será definitiva y participa allá arriba cachuriando (recolectando): cartones, diarios y botellas, también se vuelve integrante de un sindicato de cartoneros. La tercera etapa se caracteriza porque la venta de diario se hace en las carnicerías y en la feria de abastos, la casa se adecua para el acopio, establece una relación comercial con una empresa que los retira e inicia la venta de cachureos, lo cual originará la cola. La cuarta etapa está marcada porque su pareja muere, continúa cachuriando y una enfermedad le impide seguir con esos desempeños económicos.

La segunda trayectoria es de cachurerocachurero desde la infancia y sin cambio de ocupación, se define de la siguiente manera: desde muy temprana edad recuerda que se encuentra buscando recursos para alimentar a sus hermanos y ayudar a su madre, incluso deja de comer lo que logra para entregárselo a los más pequeños integrantes de la familia. Luego, cuando tiene su familia, se ubica como cachurero abierto a recibir informaciones para mejorar ese desempeño. Por ejemplo, pasando del carretón al triciclo o informándose para saber dónde se pueden captar mejores cosas y abandona la idea de buscar empleos en otros mercados laborales.

En el otro extremo. La tercera generación tiene edades que van entre los cinco y los veinte años, continúa con la posibilidad de trabajar en la cola sin que les sea extraño dicho desempeño. Sus vidas en los jardines infantiles y en las escuelas públicas, los diferencia de la primera generación, la cual gastó su infancia y juventud para ayudar a sus madres, hermanos y después para lograr su sustento.

Caracterizamos a esta tercera generación a través de la trayectoria obrero colero obrero, la cual se inicia cuando se reconoce el origen en una familia que produce lo que vende en la feria, por lo que su infancia se 
relaciona con lo que hacen los adultos. En una primera etapa hay desempeños regulares en sistemas educacionales hasta finalizarlos y participación en plazas laborales asalariadas. En una segunda etapa se hereda el puesto porque su propietario vive una enfermedad que lo invalida o muere. En una tercera etapa mezcla el desempeño asalariado con las actividades de colero, y diversifica lo que tradicionalmente ofrecía el puesto, debido a que aprende sobre los consumos de las personas según: género, edad, tiempo social y estación del año, lo cual explica la inversión que hace. En la cuarta etapa continúa mezclando las plazas laborales, participa en las actividades del sindicato pero el trabajo asalariado es más relevante en su identidad laboral y en los recursos monetarios que aporta, impidiendo mantener la continuidad en la cola, por lo cual pierde el puesto.

Entre la primera y la tercera generación se han reconocido 4 tipos ideales de cursos de vida que caracterizan a los hombres, y 5 tipos ideales que describen a las mujeres. Para los objetivos del presente artículo sólo presentamos 2 trayectorias de vida de mujeres.

Trayectoria A. La vida es rememora sin pasar por su niñez e inmediatamente se presenta como una persona que se ha abocado a criar a sus hijos y a las labores del hogar. En una primera etapa su desempeño está en las labores como dueña de casa. En una segunda etapa cuando sus hijos ya comienzan a terminar la educación básica y universitaria, se produce un umbral que dota de contenido al hito aburrida. A partir de ahí reflexiona junto a su familia sobre las posibilidades de iniciar una actividad distinta a las del hogar, encontrándola en la venta al detalle y haciéndose parte de la cola. En una tercera etapa mezcla sus desempeños en las labores de su hogar con el quehacer en la cola, participando con su pareja en el mantenimiento de la organización económica, del sindicato e inicia la elaboración de proyectos que serán presentados en la municipalidad.

Trayectoria B. La vida es rememora sin pasar por la niñez e inmediatamente se presenta como una persona que se ha abocado a criar a sus hijos, a las labores del hogar y a trabajos apatronados sin tener la cooperación de un hombre. En la primera etapa hay desempeños en plazas laborales asalariadas que se cierran para dar paso a un periodo de cesantía y de necesidad, lo cual conduce a realizar "pololos" brindando servicios a domicilio: "aseo profundo", cocinar y/o planchar, también se realizan actividades de alimentación, aseo y cuidado de los miembros dependientes del hogar. La segunda etapa se presenta con una mezcla de: trabajos asalariados, actividades de crianza y del cuidado del hogar, participación en las organizaciones de los vecinos y en la autogestión de una plaza laboral en la cola. La tercera etapa mezcla su plaza laboral apatronada, las labores dentro de su hogar, continúa participando como delegada en las organizaciones vecinales y en la cola se incorpora a las reuniones y a los cargos de la directiva del sindicato.

En resumen, las trayectorias de vida que describen a las generaciones que han conformado el emprendimiento asociativo de trabajo 
autogestionado, nos señalan las bases gracias a las cuales se realiza. Es decir, por un lado, la necesidad es un hito de la memoria compartida que explica la emergencia de la cola; y, por otro lado, la mezcla de las labores en las distintas situaciones de mercado: doméstico, por cuenta propia y asalariado, indican el desarrollo de la capacidad de combinación de los diferentes saberes que se logran y que cada colero pone a prueba en su comunidad efectiva para administrar la organización económica.

\section{Las comunidades efectivas de la cola}

El trabajo en cada puesto está cerrado a la intervención de otros coleros. Sin embargo, hay relaciones que permiten abrir esta clausura, entre ellas la atención de la venta, lo cual inaugura la coordinación de las funciones de cada trabajador en la cola. Su relevancia se comprende si se considera que la venta es un mandato cultural y la oportunidad no se debe dejar pasar para que se concrete. Un paso más allá. La venta supone un repertorio de roles definidos que borran las fronteras fijadas por la edad y el género, simplemente se despliega con independencia de las cualidades de los que interactúan. En este ámbito todos pueden participar.

Otra interacción que es parte de esa relación es el cambio de dinero por dinero, la cual permiten recursos monetarios al detalle para "dar el vuelto” cuando el comprador ha pagado con un billete grande. Esta complementariedad se transforma en una coordinación que gesta un acumulado histórico entre quienes participan, especialmente porque el colero que brinda ese servicio logra confianza con los que habitualmente no conversa y esa función lo incluye en la trayectoria del emprendimiento asociativo. Incluso, esas membresías con distintas confianzas lo acercan a los datos.

Estas variedades de la convivencia muestran que la distancia social reducida a su máxima posibilidad gesta el sentido de pertenencia. Por tanto, los coleros hablan ahí de lo mismo y conciben la idea de un nosotros, que se define como todos los que participan en fragmentos conexos de encuentros definidos: vender y cambiar, que hilvanan los marcos de apreciación en esas relaciones de mercado.

La compra y venta entrecoleros expertos es otro tipo de interacción que reviste relevancia. Esta se realiza cuando ellos estudian a las personas que están en los puestos desde lo que ofrecen, la rutina es observar y preguntar. Así, el que vende debe describir la historia de la cosa e indicar las condiciones en las cuales se encuentra.También es común que la prueben y le busquen usos alternativos a todo el artefacto o a sus partes. A continuación, se produce una conversación cuyo contenido devela lo que está en juego: precios, usos reales y posibles y el tiempo de duración. En ese transcurso cada cual muestra lo que sabe y se permiten disputas por la traducción del valor al precio. 
Estos coleros expertos son todos hombres y se caracterizan porque pertenecen a comunidades efectivas que presentan una cohesión y clausura correspondiente a: 1 . Red de parentesco con coexistencia de organizaciones económicas en el puesto, 3 . Vínculos desde el cambio dinero por dinero, 4. Colero incluido pero solo, 6. Coleros Pareja: apertura y coordinación a través del hombre pareja, y 9. Colero con puesto y con un pequeño núcleo denso. Más adelante comprenderemos por qué las mujeres y los niños no participan como coleros expertos.

Por otro lado, los coleros expertos poseen un nivel de apertura y coordinación que se caracteriza porque participan en conversaciones que están fuera de las relaciones consanguíneas y de parentesco, donde se busca entregar o recibir datos, los cuales pueden ser diálogos sobre las adaptaciones de los artefactos, incluso su desarme y la venta de sus partes. Además, entre ellos se brindan asistencia a través del préstamo de herramientas.

La ubicación de antiguogesta una diferencia entre los expertos porque sólo algunos dedican toda su vida a las actividades de la cola. Un caso especial son los coleros que compran al por mayor y venden al detalle, porque logran que su organización económica trascienda la cola y se ubique como un proyectocuando es presentado a una organización no gubernamental que brinda préstamos para "hacer más negocio". Esta relación intersectorial sólo se logra sobre la base de acuerdos entre expertos, cuando se evalúan y se proponen cambios de rutina, se organizan para resolver los problemas de la gestión de sus negocios y estiman evaluaciones sobre las ganancias.

Los coleros expertos y los expertos antiguos no se incorporan a la comensalidad de bebidas alcohólicas y no buscan analizar el gobierno político de la cola con los dirigentes. Por el contrario, los dirigentes se ponen en contacto con ellos.

En nuestro estudio hemos elaborado 13 posiciones típicas de comunidades efectivas según su cohesión y clausura y apertura y coordinación, las cuales se aprecian en la tabla número 2 que se encuentra a continuación. En este artículo, solo enunciamos las que corresponden a los niños, coleros en parejas y coleros volantes, porque explican la división del trabajo por género, conducen a la transmisión de los saberes socialmente aceptados y al sindicato. Mantenemos sus códigos para facilitar el recorrido por la tabla que se presenta al final de este acápite.

Tipo 2. Hijos de coleros y cachureros en el puesto.La clausura que resulta de la cohesión de la red parental y consanguínea impide que los niños tengan vínculos amplios y diversos, incluso entre ellos. Por tanto, los niños se socializan ajustados a los contenidos de la cultura económica reproducida por los adultos, también son ellos los que les permiten acceder a las informaciones sobre la gestión política de la cola, a las evaluaciones sobre los beneficios económicos y a los modos de apropiación simbólica. 
Los niños trascienden esta cohesión incorporándose a vínculos diferentes con coleros no emparentados, cuando estos últimos han realizado las siguientes prácticas: resuelven los problemas de la venta del puesto, debido a que participan atendiendo las preguntas, acceden al recurso económico y demuestran honradez dentro de la gestión de la organización de la familia del niño; entregan regalos a los niños con la previa aprobación y supervisión de los integrantes de su familia y participan en la distribución y consumo de los alimentos a la hora del desayuno o del almuerzo.

Tipo 6: Coleros Pareja: apertura y coordinación a través del hombre pareja. Los coleros pareja son un hombre y una mujer que conviven con o sin formalización civil o religiosa, se caracterizan porque contribuyen a una economía doméstica a través de los desempeños que realizan en una organización económica en el puesto, juntos revisan la gestión política de la cola, evalúan los beneficios de las ventas, acceden a informaciones sociotécnicas que ayuda a mejorar las condiciones de trabajo o a la adaptación de los cachureos. Las mujeres se abocan a las gestiones del puesto, co-construyen la comensalidad con sus parejas y no participan en relaciones diversas.

Por su parte, los hombres trascienden la pareja y acceden a interacciones donde se analiza la gestión política de la cola, los usos reales y potenciales de los artefactos, por medio de lo cual acceden a cuotas de reconocimiento sobre su calidad deexpertos; conversan con otros hombres sobre la vida cotidiana y compran cachureos que luego serán vendidos a un mayor precio.

Tipo 11: Coleros volantes con vínculos fuertes y acceso al sindicato. Estaposición se caracteriza porque la o el colero volante o visita, acepta la donación de un espacio para ubicar las cosas que trae y realiza la reciprocidad mediante el cuidado de la gestión económica y de los artefactos del colero donante. En esta reciprocidad conversa sobre la gestión política de la cola.

El o la colera volante se relaciona con sus vecinos a través de conversaciones sobre asuntos de la vida cotidiana, con ellos se organiza para resolver los problemas de la coexistencia en la cola y entabla conversaciones con los coleros que no son vecinos y/o son dirigentes, permitiéndole un reconocimiento que le garantiza una forma de membresía al sindicato. Además se vincula a otros coleros no emparentados a través de la donación de lo que ha traído para la venta, mientras que los que aceptan la retribuyen con reconocimiento. 


\section{Tabla 2 \\ Tipos ideales de comunidades efectivas en el sistema de relaciones de la cola EEUU}

\begin{tabular}{|c|c|}
\hline Tipos ideales de comunidades efectivas & Clasificación de casos según tipo de comunidad efectiva \\
\hline \multicolumn{2}{|l|}{ Parentesco con coexistencia de organizaciones económicas } \\
\hline $\begin{array}{l}\text { Tipo 1: Red de parentesco con coexistencia de } \\
\text { organizaciones económicas en el puesto }\end{array}$ & $\begin{array}{l}\text { Marco, Nina y su hija Jazmin; y Carlos y su hija; Hijastra, tres } \\
\text { hijos de hijastra. }\end{array}$ \\
\hline Tipo 2. Hijos de coleros y cachureros en el puesto & Maxi, Fabián, Dylan, Femando e hijo Alejandro \\
\hline \multicolumn{2}{|l|}{ Colero sin cohesion y clausura, y coordina do } \\
\hline Tipo 3: Vínculos desde el cambio dinero por dinero & Raúl el calcetinero y señora \\
\hline \multicolumn{2}{|l|}{ Colero solo } \\
\hline Tipo 4: Colero incluido pero solo & $\begin{array}{l}\text { José negro e hija; Pelao e hijo; Mantza e Hija; Rosa y Claudio y } \\
\text { Rucia e hijo }\end{array}$ \\
\hline Tipo 5: Colero incluido por donación pero solo & Zapatero de abajo \\
\hline \multicolumn{2}{|l|}{ Coleros Pareja } \\
\hline $\begin{array}{l}\text { Tipo 6: Coleros Pareja: apertura y coordinación a través del } \\
\text { hombre pareja }\end{array}$ & $\begin{array}{l}\text { Don Tito y Mujer; Sordo, hijo joven y señora; Amando y Sara; } \\
\text { Mario y señora; Roleny señora; Choro polilla y señora; Don Lalo } \\
\text { y Marina; José payaso y Lorena y Francisco y Nanci. }\end{array}$ \\
\hline Tipo 7: Coleros Pareja que compran y ayudan & GC y Minam GC \\
\hline \multicolumn{2}{|l|}{ Coleros con pocos vinculos fuertes } \\
\hline Tipo 8: Mujeres emparentadas & $\begin{array}{l}3 \text { Mujeres; Mujer abuela, mujer nuera abuela (Mujer X), hija de } \\
\text { abuela (Nancy), Ana; Rosa e hija de rosa y Paty } 1 \text { y nuera }\end{array}$ \\
\hline Tipo 9. Colero con puesto y con un pequeño núcleo denso & $\begin{array}{l}\text { Peruana; Raúl; Raúl (pariente Amando); Pulga; Sergio; Vendedor } \\
\text { de libros; Zapatero de amiba; Paty 2; José Bigote; Noemi; Raúl } \\
\text { (Vendedor delentes)y Mujery hombre venden accesonos de aseo. }\end{array}$ \\
\hline \multicolumn{2}{|l|}{ Coleros volantes } \\
\hline $\begin{array}{l}\text { Tipo 10: Coleros volante con un pequeñonúcleo denso y sin } \\
\text { acceso al sindicato }\end{array}$ & Colero A \\
\hline $\begin{array}{l}\text { Tipo 11: Coleros volante con vínculos fuertes y acceso a } \\
\text { sindicato. }\end{array}$ & Arco y flecha y hombre y mujer vendedores de CD y DVD \\
\hline \multicolumn{2}{|l|}{ Colero dingente de la cola } \\
\hline $\begin{array}{l}\text { Tipo 12. Colero con puesto y vinculado a través de su } \\
\text { pasado como dingente de la cola }\end{array}$ & Juan Vildo; David; Carlos \\
\hline $\begin{array}{l}\text { Tipo 13. Colero con puesto y vincula do a través de ejercicio } \\
\text { como dirigente de la cola }\end{array}$ & Ruth; Jenny; Lily y Alejandro. \\
\hline
\end{tabular}

Fuente: Elaboración propia

\section{El sindicato de Coleros de Huechuraba: CODEHUE}

El sindicato es una innovación que emerge gracias a que los coleros lograron administrar las rutinas de interacciones que ya se venían dando en las comunidades efectivas de la cola, específicamente: reunir una cuota para hacer un fondo y la asamblea. A estas se agregaron: la deliberación sobre los espacios vacíos, la certificación de la membresía y las relaciones con la municipalidad. Su ideación está basada en los criterios de: orden, libertad para fijar los precios, paz y limpieza.

La trayectoria del sindicato tiene tres hitos. El primero fue un enfrentamiento con el gobierno local que quiso erradicarlos. La situación fue entendida como la pérdida del derecho a trabajar en lo propio. Entonces, según los primeros integrantes del sindicato y de los coleros antiguos, ellos comenzaron a protestar frente a la municipalidad durante algunos días de la semana. Posteriormente "los de la muni" propusieron un acuerdo donde se les entregaban en comodato la calle, mientras que los del sindicato debían empadronarse, marcar los puestos y dejar limpio. Cuando empezaron a ocupar la calle se incluyó un nuevo participante que los rechazaban y "correteaba”, estos fueron los vecinos de esa calle. La primera directiva 
del sindicato visitó a cada uno para explicar el horario de uso de la calle, sus objetivos y las medidas de limpieza que adoptarían.

El segundo hito fue una etapa de buena acogida donde "la alcaldesa nos orientó mucho más de lo que nosotros sabíamos”, se entregó la calle y los apoyos para llevar a cabo los paseos a la playa. Estas relaciones legitimaron al sindicato y a la cola como actores económicos en la política de la comuna.

El tercer hito está conformado por las renovaciones de su directiva donde se subraya la disolución de la segunda, porque no hubo "quién nos auspicie”, guie, se hagan cargo, la “gente empezó a hablar que la plata no se veía”, se perdió el baño y no se cumplieron los objetivos que se propusieron.

Entre el primer y segundo hito, la directiva realizó comenzalidad sobre la base de compartir alimentos, lo cual dio respuesta a la necesidad del almuerzo. Así creó unfondo para cocinar entre todos y el resultado fue: "todos nos uníamos, se conocía la gente, que mucha gente no se conocía y la cosa era pasarla bien”. Este periodo fue de reciprocidad generalizada, en menor medida balanceada, y destacó la intensidad de los intercambios de donación, su alto grado de eficiencia y un flujo de bienes y servicios.

\section{Las asambleas}

Desde la conformación del sindicato se han realizado reuniones en edificios municipales, en el pasillo de la cola, en el puesto de David, en la plaza de la calle y en Juntas de Vecinos. Todos estos encuentros son a viva voz y de frente a la mirada atenta de los coleros. Las reuniones conminan a tomarse en cuenta o "somos una familia y debemos protegernos unos a otros”. Pero también se observó que las distintas comunidades efectivas cumplen con ser asambleas donde se observa, reflexiona y decide sobre la gestión política. En las asambleas convocadas por el sindicato CODEHUE, se tratan los siguientes asuntos:

A. Se revisa la libreta de ahorro para observar el fondo. La cuota depende de lo que dice la gente sobre: el monto del dinero, los tiempos de pago, la obligatoriedad o no de esos pagos y las razones que permitirán usar el recurso reunido. Los registros se llevan en un cuaderno de cuotas.

B. La membresía es empadronarse, administrar y marcar los puestos. Esta información se apunta en el registro de socios.

C. Se quitan y asignan puestos mediante una lista de coleros visitas, por lo cual accederán a un espacio vacío y pagarán una cuota.

En las asambleas las relaciones familiares son una buena recomendación para lograr un puesto cuando aparece la oportunidad. Sin embargo, 
no son antecedentes suficiente debido a que el puesto no es heredable por la sangre y cuando ocurre se debe a que el que lo ha recibido cumple los acuerdos colectivos: trabajar el puesto y avisar cuando no asiste. Una excepción a este procedimiento son los vecinos cuyas casa colindan con la cola, lo cual se da en 3 puestos, con los cuales se convino entregarles un espacio mientras ellos se encargan de guardar los basureros y brindar energía eléctrica para probar los artefactos que están a la venta.

Para la asignación de un puesto es habitual una reunión pública frente al espacio vacío. Con el tiempo se agregó que la visita no debía vender cosas similares a los vecinos, y si así fuera tenía que ser asignada en otro lugar. En todos los casos de asignación de puestos participó un integrante de la directiva y los reclamos provenían de coleros que no asistían a las reuniones de la asamblea, esa falta de información les alentaba temores que fueron aplacados porque siempre los dirigentes le transmitieron las decisiones colectivas.

Esta forma de asignar los puestos redujo y sancionó el intento de algunos para crecer en cantidad de metros. Y si bien en la cola no se observaron desencuentros con violencia, sí se tienen narraciones donde se recuerda que un colero ha increpado y amenazado a otro hasta "corretearlo" y dejarlo sin puesto. Con el sindicato estas situaciones no pasan. Por ejemplo, Francisco recuerda que un día llegó un hombre que no sabía convivir, venía a puro pelear y los chiquillos lo apoyaron y el hombre se tuvo que retirar.

El día 22 de marzo de 2015 se produjo una reasignación de puestos, en algunos casos fueron confirmados, en otros los coleros dejaron de ser visitas y hubo puestos que desaparecieron porque sus habituales trabajadores no asistían y no fueron a las reuniones del sindicato. Durante dos meses los comentarios fueron críticos porque unos asumían que los habían perjudicado, mientras que los beneficiados guardaban silencio. Con el paso del tiempo las tensiones bajaron porque se acostumbraron a las nuevas posiciones.

D. Se analiza la relación con la municipalidad, especialmente los beneficios logrados, el cumplimento de los acuerdos y las ofertas de capacitación y concursos para obtener recursos que ayudan a implementar proyectos. En estos términos, la municipalidad arriba a través defuncionarios y documentosque impulsan a los coleros a lograr consensos operativos sobre tres tópicos: los límites de cada puesto, la legitimidad de su uso y la elección de su directiva.

La relación entre la tercera directiva del sindicato y la encargada territorial de la municipalidad, permitió realizar talleres para los niños que estaban en los puestos. Esta iniciativa nunca antes se había hecho a pesar que siempre hubo niños coleros, en el taller de medioambienteparticipa el hijo de Alejandro, las niñas de Carlos y una monitora. 
E. Modales, aseo y ornato. Se discute el uso de los garabatos, el consumo de alcohol y otros asuntos que son escritos en un libro de novedades. Dentro de los problemas se encuentra la administración del baño químico y público que aportó la municipalidad, y que fue gestionado por la primera directiva sobre las necesidades de los niños y mujeres de la cola. La segunda directiva lo perdido, la municipalidad no lo volvió a poner y fue gestionado nuevamente por la tercera directiva. Al principio de esta administración cada integrante tenía llaves del candado de la puerta del baño, pero su realización recaía en Ruth, José y Alejandro. Con el paso del tiempo las llaves se extraviaron, las personas que las tenían no estaban y varias veces se rompieron los candados. Así el baño quedo abierto y disponible para todos.

\section{El colero dirigente}

Gracias a la existencia del sindicato se articuló una ética social y un saber sociotécnico que permite que emerja el rol del dirigente. En el segundo ámbito, el saber está referido a los procedimientos para lograr situar al sindicato dentro del mapa sociopolítico y administrativo de los que trabajan en "la muni", lo cual se refleja cuando se subsume a la organización en la categoría de organizaciones comunitarias. Desde ahí se plantea la conversación con las autoridades. Según los coleros, esa inscripción en la política pública local se nombra como "tiene la mano" con "la muni”, por lo cual son los dirigenteslos que gestionan el conducto regular de los aportes municipales que van a complementarse con los propios para llevar acabo las actividades que se han acordado en la asamblea.

Así, la categoría sociolingüística dirigente se encuentra vinculada al municipio y a la gentepor la cual se está dispuesto a responder o "jugársela por los demás”. Cuando el rol se define en este segundo sentido, su semántica se ata a las ideaciones verbalizadas de la siguiente manera: "los que guían", "se hacen cargo" y "ser bien y correcto que todos nos beneficiemos, no algunos".

Se ha entendido que hay dos cargos que son difíciles de realizar, el de presidente y el de tesorero. El primero porque debe saber llegar a acuerdos con la municipalidad y con los coleros, mientras que el segundo supone guardar un fondo y cobrar las cuotas. Esta última actividad ocupa bastante tiempo durante los días domingos y promueve una falta de cooperación entre los integrantes de la directiva porque su implementación es más que engorrosa, incluso Yenni se retiró de su puesto y del cargo de tesorera porque no estuvo dispuesta a recibir un maltrato domingo a domingo, y los demás dirigentes no querían realizarlo porque era un ejercicio desgastante y muy expuesto a malas palabras. Por estos hechos, la asamblea decidió que la cuota fuera voluntaria y sus beneficios para los que la pagaran, y no para todos los que aparecen en el libro como socios. Finalmente, la resistencia al pago de la cuota se comprende si se recuerda que hubo una mala gestión del fondo en la segunda directiva del sindicato. 


\section{Las fuentes de la autoridad del que enseña}

Hemos advertido que las relaciones de parentesco son variables que están presentes en la cola. Sin embargo, no observamos que sean las fuentes de una organización vertical. Las relaciones de parentesco por línea materna, de hermanas o mujeres emparentadas, condición presente en 6 puestos, fortalece la búsqueda de la proximidad física. Por el contrario, la consanguineidad entre hombres no presenta la misma expresión pero son ellos quienes cuidan a los hijos y nietos.

A modo de ejemplo. En el puesto de Raúl se comparte con el niño Dylan cuyo abuelo es don Tito, también participa el vecino Pulga. Estos hombres generan un clima para Dylan porque le entregan lo que ellos no tuvieron cuando niños: comida, juguetes y trato amable. Por su parte, el niño juega aprendiendo que su alegría es gracias a que cuida el respeto por los demás, se introduce en los pregones y en la forma de atender a los clientes. Allá arriba, en el otro extremo de la cola, José le grita a su hijo Fernando y humaniza la socialización. Educar aquí es criar a través de experiencias públicas: sufrimiento, aburrimiento, sueño, todos los estados de un niño figuran la convivencia de la crianza y sus experiencias se hacen parte del ser colero. El colero cría a su descendencia y los niños se crían ahí.

Lo común es que en esas relaciones se despliegan los comentarios que educan sobre cómo fijar los precios: "Lo único que le decía yo: no vendai tan barato esto, véndelo a tal precio. Usted no saca nada con ir con el cachureo a venderlo a precio barato, si también cuesta”; las formas de atenciónal potencial comprador, "para poder atender al público uno tiene que estar contento y no traer lo que le pasa, dejarlo atrás, botarlo y cuando vuelve, como que vuelve a un estado normal, anterior," y los datos que refrendan que lo logrado debe ser usado para "cosas útiles que sirvan, y no andar botando la plata”.

Criar para las coleras es darle leche al niño y el niño amamanta en la comensalidad del puesto: lo hace Lorena con Fernando, su vecina de enfrente, la hijastra de Calos con su hija, también Nina con su hija Jazmín. En los momentos de esperalas mujeres con hijos pasan el aburrimiento jugando con lo que está a la venta, o el niño las introduce al juego de vender usando los pregones que ha escuchado. Todos los juegos son suspendidos cuando la pregunta por una cosa cambia el marco de la interacción. A partir de ahí, los niños participan en el cambio de dinero por dinero y pueden atender la venta.

De esta manera la expresión aquí se han criadoindica la eficiencia de las interacciones que han facilitado aumentar la densidad de las ideaciones, en su despliegue el nuevo integrante aprehende. Sin lugar a dudas son las interacciones de regateo las que invisten de reputación a sus participantes, porque se fundamentan en las combinaciones y usos de las informaciones probadas como eficientes, por ejemplo: saber atender y saber qué vender. Así las palabras que transmiten esos conocimientos son aceptadas como 
buenos datos por los que escuchan y preguntan, con lo cual ceden sus voluntades y transforman al orador en una autoridad y a esas interacciones en "núcleos de sociabilidad” (Ratier, 2004, p.84).

\section{La ética social de la cola}

El obrar colectivo que crea la vida económica que hemos revisado, forja un conocimiento situado que reporta seguridad ontológica mediante las siguientes razones socialmente aceptadas, a saber: libertad, transformación de las cosas en recursos monetarios y la obligación de brindar asistencia a quién tiene una necesidad.

La libertad es lo querido y gusta en la administración del trabajo. También lo querido para decidir lo que debe gobernar las relaciones ("nadie manda”, "hacís lo que querís”, “yo puedo hacer y deshacer”), la flexibilidad para mezclar los tiempos, los dedicados a cachurear ("llegari a la hora querís”), los de la familia y para hacer otras cosas. Para algunos integrantes de la cola, esta es la costumbre que impide lograr una trayectoria dentro de las plazas laborales apatronadas.

Por otro lado, cuando la transformación de las cosas en recursos monetarios se expresa como un trabajo, y se articula con la obligación de brindar asistencia a quién tiene una necesidad, se constituye un mandato cultural que legitima el uso del espacio público. Por eso, el puesto es un derecho para cumplir esa obligación. Esta particularidad de la ética ayuda a que emerjan los consensos operativos que justifican la coexistencia de los coleros. La estabilidad de este componente de la matriz de sentido se expresa de varias formas, pero la manera de evaluar y asignar los espacios constituye su caso ejemplar, porque demuestra la coherencia cultural de las comunidades efectivas que reproducen colectivamente la tecnología social que estudiamos.

En esa visión del mundo, los coleros toman conciencia que la cola es una posibilidad para las personas que necesita recursos monetarios, y como han participado en asistencia similares que les resolvieron sus problemas, renuevan ese derecho a trabajar gracias a la obligación de devolver la donación ya aceptada y usada. Por su parte, el colero visita se conoce por su modo de aproximación, mediante lo cual indica si conoce o no las reglas del comportamiento colectivo. Ahí lo correcto es preguntar a los que están al costado, escuchar y aceptar lo que dicen para orientarse. Entonces, se requiere que la solicitud de uso de un espacio vacío quede a merced de un escrutinio colectivo en esa asamblea. Por su parte, los coleros del sindicato se forman una idea sobre el tipo de vendedor que es, o sea: si llega a una hora apropiada incluso se lo podrá ver como competencia, mientras que su reputación baja si aparece cuando el "choclón de gente ha pasado". También saben que si el encuentro se vuelve tenso como resultado de una disputa, se debe recurrir a los dirigentes. 
En algunos casos donde no se permite usar un espacio vacío el demandante puede enfrentar la sanción, y el argumento de fondo será el derecho a trabajar. Entonces, no apela a lo público, lo cual se debe a que todos habitan el mismo mundo económico, y ahí ven cola y no calle.

El límite de la ética social de la cola se encuentra en el estado de la convivencia dedicada al consumo de alcohol, donde se producen dos transformaciones. La primera es el uso del recurso monetario logrado para comprar cervezas y vino, lo cual cambia al colero en "tomador". La segunda se inscribe dentro de un patrón de integración estratégica porque algunos individuos aprovechan los beneficios de la cooperación. Entonces, las relaciones que permiten reunir el fondo para adquirir bebidas alcohólicas no son usadas para asistir a uno de sus integrantes cuando tiene necesidad. Pero antes que ese patrón sea evaluado negativamente se producen varias relaciones de "reciprocidad negativa" (Lomnitz, 2005), especialmente porque el que no ha sido asistido perdona, olvida y sigue cooperando.

\section{El trabajo}

En la ética de la cola el trabajo se entiende como: felicidad, "hacer plata”, despliegue físico y sin vergüenza. Esto último sería similar a lograr dignidad, honradez y credibilidad. A continuación, la expresión "mi trabajo vale” refleja una apreciación sobre la felicidad que reporta el ganar plata, mientras que su despliegue transforma a la persona en un trabajador.

El trabajoes un mandato cultural porque dota de coherencia a la organización económica en su trayectoria y articula los conocimientos sociotécnico que responden los problemas intersubjetivamente relevantes. Su objetivo pragmático es "hacer plata", y así el trabajo pasa a ser una búsqueda porque "la plata no te llega a la casa", y ese desempeño ("jugándotela") ayuda a estar vivo dignamente o a "no ser hombre muerto". Los opuestos al trabajo son: el vicio, “pasan puro tomando no ma'”, el ocio $\mathrm{y}$ el robo.

Cuando describimos las trayectorias de vida reconocimos que los coleros no se inician en el trabajo porque han nacido en su interior: "si yo soy nacido y criado allá”. Su vida de trabajo no tuvo deliberaciones sobre el uso de la fuerza física y las capacidades de la razón para lograr recursos monetarios, cuando lo primero faltó la segunda orientó la búsqueda de cosas para acometer el objetivo "pa’ hacer plata, pa’ tener para el día”.

Esta concepción del trabajo, inherente a esta tecnología social, reconoce la mezcla de actividades para obtener recursos monetarios. Por lo cual, hilvana las trayectorias de vida entre plazas laborales autogestionadas y desplegadas sobre reciprocidades y coordinaciones de funciones en emprendimientos asociativos, con las del mercado de trabajo urbano asalariado: flexibles, terciarizadas y con fecha de vencimiento. Esas mezclas homogeneizan a las distintas generaciones de coleros, porque están dispuestos a surgircombinando mundos económicos. 
Polis, Revista Latinoamericana, $N^{\circ}$ 47, 2017

\section{Conclusión}

La cola está conformada por trayectorias de vida donde la socialización en la familia es la que reproduce los roles de esta tecnología social, y es esa socialización el antecedente de las mezclas de las plazas laborales que ofrecen otros mercados de trabajo. Desde ahí son relevantes las mujeres y los hombres que no viven exclusivamente de la cola, porque ellos introducen concepciones que promueven innovaciones en su gestión.

La cola, en su marcha cotidiana, se despliega mediante diversos tipos de comunidades efectivas, al menos 13, las cuales presentan dos similitudes: poseen una cohesión que cierra y diferencia sus comunidades de trabajo, y el género limita o amplía las posibilidades de incorporación a los encuentros donde se analiza la gestión política o están las informaciones que ayudan a mejorar las condiciones de trabajo.

Al considerar la apertura y coordinación, hemos observado que son las mujeres las que inclinan la balanza cuando se pasa de la evaluación de un problema que afecta al obrar colectivo a la implementación de la solución, lo cual se concreta a través de las asambleas y el sindicato. Los hombres destacan en aperturas abocadas a cumplir el mandato cultural por el cual se está en el puesto, mediante sus accesos a los datos que los transforman en expertos.

Una posición relevante es ocupada por los coleros que trabajan solos, por ejemplo, los volante con vínculos fuertes y acceso al sindicato, debido a que su cohesión y clausura está desplazada hacia las relaciones con otros con los cuales han compartido reciprocidad y mantienen interacciones horizontales que desenvuelven obligaciones que son eficientes en la gestión de la comercialización y la inversión.

Hay otros dos elementos comunes que caracterizan el desplazamiento desde la gestión individual a la colectiva. Por un lado, la comensalidad es una rutina que se vuelve tradición. Desde aquí es posible sostener que el colero asiste a la cola para darle continuidad a esa fraternidad que le reporta apoyo socioafectivo y, como consecuencia, participa en la venta y en el regateo. Por otro lado, las relaciones entre ellos y los que implementan las decisiones de la asamblea del sindicato están habitualmente mediadas. Esto explica la relevancia de los coleros dirigentesporque coordinan a las comunidades efectivas con pocos vínculos fuertes. Esa función les ayuda a tener una fuente de reconocimiento y prestigio, pero no los trasforma en expertos.

La tecnología social que hemos descrito basa su coherencia cultural en la ética que orienta la forma de asignar los puestos, debido a que funda derechos en la reciprocidad alternante e indirecta. Ahí, ceder el derecho para vender, es fuente de la confianza interpersonal que norma todas las demás obligaciones de la familiaridad de esa convivencia, su aumento de complejidad es el sindicato y su regla es la siguiente: brindar asistencia 
cuando otra persona demuestre vivir una necesidad. Esta condición homogeniza a los coleros y restringe las acciones que entienden al puesto como propiedad privada o alientan su acumulación. 
Polis, Revista Latinoamericana, $N^{\circ} 47,2017$

\section{Nota}

${ }^{1}$ Este artículo es un producto de la investigación n ${ }^{\circ}$ PROV.: 11130329 del FONDECYT Iniciación en la Investigación 2013-2015. 


\section{Bibliografía}

Bourdieu, P. (2007).El sentido práctico. Buenos Aires, Argentina:Siglo XXI.

Dagnino, R. Brandâo, F. y Novaes, H. (2004). Sobre o marco analíticoconceitualdatecnologia social. En Tecnologia social: umaestratégia para o desenvolvimento. Rio de Janeiro, Brasil: Fundação Banco do Brasil.

Forni, F. (1992). Formulación y evaluación de proyectos de acción social.Buenos Aires, Argentina:Humanitas.

García, Á. (2004). Forma valor forma comunidad. La Paz, Bolivia: Muela del Diablo.

Godelier, M. (1996). El enigma del don. Barcelona; España:Paidos.

Gómez, N. (2014).Tecnología social. Comunidades en despliegue, enfoques teóricos y usos particulares. Revista Otra Economía, 8 (15), 118127. doi: 10.4013/otra.2014.815.01

Granovetter, M. (1973). The Strength Of Weak Ties. American Journal of Sociology 78.

Hardy, C. (1985). Hambre + Dignidad = Olla Común. Santiago, Chile: PET.

Hirschman, A. (1984). El avance de la colectividad. Experimentos populares en la América Latina. México D.F., México: Fondo de Cultura Económica.

Lomnitz, C. (2005). Sobre reciprocidad negativa. Revista de Antropología Social, 14(0), 311-339. Recuperado de https://revistas.ucm.es/ index.php/RASO/article/view/RASO0505110311A/9493

Lomnitz, L (1978). Mecanismos de articulación entre el sector informal y el sector formal urbano.Revista Mexicana de Sociología, 40 (1), 131153.

Lozares, C., Verd, J., y Barranco, O. (2013). El potencial analítico de las redes socio-métricas y ego-centradas: una aplicación al estudio de la cohesión-integración de colectivos sociales. EMPIRIA. Revista de Metodología de Ciencias Sociales, (26), 35 - 62. doi: 10.5944/ empiria.26.7152

Luckmann, T. (2008).Conocimiento y Sociedad. Ensayos sobre acción, religión y comunicación. Madrid, España: Trotta 
Polis, Revista Latinoamericana, $N^{\circ} 47,2017$

Márquez, D. (2004).Representaciones sociales del trabajo y relaciones sociales de trabajadores independientes pertenecientes al sector informal urbano. "El caso de los coleros de las ferias libres" (Tesis de Magíster). Universidad de Chile, Santiago, Chile.

Mauss, M. (2002).Sociología y antropología. Madrid, España: Tecnos.

Max-Neef, M. (1993). Desarrollo a Escala Humana. Conceptos, aplicaciones y algunas reflexiones. Montevideo, Uruguay: Nordan-Comunidad.

Ratier, H. (2004).Pobladores bonaerenses. Vida y milagros. Buenos Aires, Argentina: La colmena.

Razeto, L. (1984).Economía solidaria y mercado democrático. Santiago, Chile: PET.

Salazar, G. (2003).Ferias Libres: espacio residual de soberanía ciudadana.Santiago; Chile: SUR.

Sen, A. (1987). Gender and Cooperative Conflicts. Working Papers (18). Recuperado de https://www.wider.unu.edu/publication/gender-andcooperative-conflicts

Schütz, A (1993).La construcción significativa del mundo social. Buenos Aires, Argentina: Paidos.

Recibido: 24.10.15

Aceptado: 30.07.16 